\title{
DEXAMETHASONE: CHONDROPROTECTIVE CORTICOSTEROID OR CATABOLIC KILLER?
}

\author{
R. Black ${ }^{1}$ and A. J. Grodzinsky ${ }^{1,2,3, *}$ \\ ${ }^{1}$ Department of Biological Engineering, Massachusetts Institute of Technology, Cambridge, MA, USA \\ ${ }^{2}$ Department of Mechanical Engineering, Massachusetts Institute of Technology, Cambridge, MA, USA \\ ${ }^{3}$ Department of Electrical Engineering and Computer Science, Massachusetts Institute of Technology, \\ Cambridge, MA, USA
}

\begin{abstract}
While glucocorticoids have been used for over 50 years to treat rheumatoid and osteoarthritis pain, the prescription of glucocorticoids remains controversial because of potentially harmful side effects at the molecular, cellular and tissue levels. One member of the glucocorticoid family, dexamethasone (DEX) has recently been demonstrated to rescue cartilage matrix loss and chondrocyte viability in animal studies and cartilage explant models of tissue injury and post-traumatic osteoarthritis, suggesting the possibility of DEX as a disease-modifying drug if used appropriately. However, the literature on the effects of DEX on cartilage reveals conflicting results on the drug's safety, depending on the dose and duration of DEX exposure as well as the model system used. Overall, DEX has been shown to protect against arthritis-related changes in cartilage structure and function, including matrix loss, inflammation and cartilage viability. These beneficial effects are not always observed in model systems using initially healthy cartilage or isolated chondrocytes, where many studies have reported significant increases in chondrocyte apoptosis. It is crucially important to understand under what conditions DEX may be beneficial or harmful to cartilage and other joint tissues and to determine potential for safe use of this glucocorticoid in the clinic as a disease-modifying drug.
\end{abstract}

Keywords: Cartilage-general, cells/tissues-injury, cells/tissues-cartilage, ECM-general, ECM-proteoglycans, cells/tissues-proliferation, cells/tissues chondrocytes.

*Address for correspondence: Prof. Al Grodzinsky, MIT, Centre for Biomedical Engineering, 500 Technology Square, Cambridge, MA, 02139, USA.

Email: alg@mit.edu

Copyright policy: This article is distributed in accordance with Creative Commons Attribution Licence (http://creativecommons.org/licenses/by-sa/4.0/).

\begin{tabular}{|c|c|c|c|}
\hline \multirow{2}{*}{\multicolumn{2}{|c|}{ List of Abbreviations }} & IL & interleukin \\
\hline & & IL-1Ra & IL-1 receptor antagonist \\
\hline $\mathrm{AA}$ & adjuvant-induced arthritis & iNOS & inducible nitric oxide synthases \\
\hline \multirow[t]{2}{*}{ ADAMTS-5 } & a disintegrin and metalloproteinase & JNK & c-Jun N-terminal kinase \\
\hline & with thrombospondin motifs 5 & $\mathrm{LDH}$ & lactate dehydrogenase \\
\hline $\mathrm{APC}$ & activated protein $\mathrm{C}$ & MMP & matrix metallopeptidase \\
\hline COX2 & cyclooxygenase II & MCP-1 & monocyte chemoattractant protein-1 \\
\hline CPPD & calcium pyrophosphate dihydrate & MRI & magnetic resonance imaging \\
\hline DEX & dexamethasone & $N F-\kappa B$ & nuclear factor kappa-light-chain \\
\hline DMOAD & disease-modifying drug & & -enhancer of activated B cells \\
\hline $\mathrm{ECM}$ & extracellular matrix & $\mathrm{NO}$ & nitric oxide \\
\hline \multirow[t]{2}{*}{ ERK } & extracellular signal-regulated & $\mathrm{OA}$ & osteoarthritis \\
\hline & kinases & PG & proteoglycan \\
\hline GAG & glycosaminoglycan & PTOA & post-traumatic osteoarthritis \\
\hline GCs & glucocorticoids & RA & rheumatoid arthritis \\
\hline i.a. & intra-articular & ROS & reactive oxygen species \\
\hline
\end{tabular}


sGAG

TA

TIMPs

TNF $\alpha$ sulphated GAG

triamcinolone

tissueinhibitors of metalloproteinases

tumour necrosis factor alpha

\section{Introduction}

GCs, a family of steroid hormones, have been used since the 1950s for treating pain and inflammation in both RA and OA, diseases associated with cartilage degeneration and joint inflammation (Creamer, 1999; Hollander et al., 1951). In the early twentieth century, new treatments for RA using extracts of animal adrenal cortical tissue led to the need for larger quantities of synthetic steroids. By the 1960s, rapid advances in chemical synthesis of GCs resulted first in synthetic cortisone, then hydrocortisone, fluorohydrocortisone, prednisone, prednisolone, triamcinolone, methylprednisolone and, finally, DEX, the latter acknowledged to be the most potent member of the GC family (Benedek, 2011).

Although the beneficial effects of GCs are now cited as well-known and accepted, there remains much controversy in the field about their prescription for patients (Hollander, 1960; Zeng et al., 2019). Harmful side effects from systemic delivery of GCs were recognised early on, leading to the pioneering development of i.a. injection for steroid therapy in the 1950s (Jüni et al., 2015). However, even with i.a. delivery of GCs, their mechanism of action in both diseased and healthy joints is not well understood. GCs can affect a variety of cellular pathways, suppressing inflammation with sometimes unknown off-target effects (Saklatvala, 2002). Even among the most recent clinical trials, there are conflicting results over their safety and efficacy, often due to low-quality evidence on their effects or different methodologies used (Conaghan et al., 2018).

The greatest concern over GC use in the context of arthritis treatment is their potential for catabolic effects on cartilage. While several clinical studies have shown significant short-term reduction in pain after treatment with GCs (Arroll and Goodyear-Smith, 2004; Conaghan et al., 2018; Hepper et al., 2009), others have revealed that with repeated i.a. injections at typically high clinical doses, GCs can lose their analgesic effects (McAlindon et al., 2017; Wernecke et al., 2015). In addition, a recent report has suggested that repeated i.a. injections every 3 months over a 2-year period cause macroscopic changes in cartilage, e.g. a loss of knee cartilage volume and thickness as measured by MRI (McAlindon et al., 2017). Animal and in vitro studies have also raised critically important issues regarding dose and duration of repeated injections. The often-cited study of Mankin et al. (1972) reported a significant loss of cartilage sGAG and suppressed matrix biosynthesis following daily intramuscular injections of $4.5 \mathrm{mg} / \mathrm{kg}$ cortisone into rabbits over a 9-week study duration. In contrast, Gibson et al. (1977) injected prednisolone (3.5 mg/kg) into mature monkey knees only once, twice or six times over a 12-week period and reported essentially no changes in injected knees as compared to controls. Was the difference in cartilage response associated with the animal species, dose, number of injections or choice of GC? Even after so many decades of clinical use of GCs, questions remain as to what mechanisms GCs act on in cartilage and surrounding joint tissues and under what dosing regimens GCs remain safe for patient use (Arroll and Goodyear-Smith, 2004; Wernecke et al., 2015).

While the most commonly used GCs today include prednisolone, triamcinolone, betamethasone and DEX, they are reported to have differential effectiveness at different doses from one another, further complicating the ability to compare and interpret treatment protocols and mechanisms of action. Therefore, the present review focuses on the effects of only one member of the GC family, DEX. This narrower focus enabled a comparison of studies on the effects of a single GC across different biological systems, from isolated cells to intact organ culture explants, animal studies in vivo and human clinical trials.

The controversy over DEX begins at the level of clinical trials. Two recent trials studying changes in pain post-knee arthroplasty surgery have used the same DEX dose, but only one found a significant reduction in pain after DEX administration (Web ref. 1; Web ref. 2). Unlike other GCs, no clinical trial has been completed that assesses the effects of DEX on cartilage structure or function; however, several recent studies have shown that DEX may have chondroprotective effects on cartilage in the context of PTOA when using in vitro human cartilage explant models [Li et al., 2015; Lu et al., 2011; Wang et al. (2014) Dexamethasone treatment alters the response of human cartilage explants to inflammatory cytokines and mechanical injury as revealed by discovery proteomics. Osteoarthritis Cartilage 25: S381-S382]. These results present the possibility of repurposing and using DEX as a DMOAD in contexts such as PTOA, where the anti-inflammatory and chondroprotective effects of DEX may prevent the progression of the disease. However, more studies must be performed to clarify the timing and dosage appropriate to obtain these effects in vivo.

While these possibilities are exciting, caution must be taken until possible chondrotoxic effects of DEX are better understood. Several studies using healthy human chondrocytes have reported that even low doses of DEX cause cell death and reduce cell proliferation, suggesting potential cytotoxic and catabolic side effects. However, the observed effects of DEX depends greatly on dose, model, duration of treatment and context (e.g. isolated cells versus intact cartilage). Thus, study conclusions often differ greatly, complicating the discussion on the safety and efficacy of this drug. It is particularly important to understand appropriate use in human disease due to the variety of reported side effects of GC treatment, 
Table 1. DEX studies in animal models summarising model used, DEX dosage and duration, frequency and administration route of DEX treatment and overall observed effect. i.a.: intra-articular injection. i.p.: intra-peritoneal injection. i.v.: intravenous injection. i.m.: intra-muscular injection. + indicates a positive effect on cartilage and/or arthritis progression, - a negative effect and $+/-$ some positive results alongside negative side effects.

\begin{tabular}{|c|c|c|c|c|c|c|c|}
\hline Authors & Year & $\begin{array}{c}\text { Animal } \\
\text { model }\end{array}$ & $\begin{array}{c}\text { Arthritis } \\
\text { model }\end{array}$ & DEX dose & Duration & $\begin{array}{c}\text { Frequency } \\
\text { and route of } \\
\text { administration }\end{array}$ & $\begin{array}{c}\text { Observed } \\
\text { effect }\end{array}$ \\
\hline Huebner et al. & 2014 & Rabbit & Yes & $0.5 \mathrm{mg} / \mathrm{kg}$ & 3 weeks & Once/3 d, i.a. & + \\
\hline Heard et al. & 2015 & Rabbit & Yes & $0.5 \mathrm{mg} / \mathrm{kg}$ & 48 h-9 weeks & Once, i.a. & $+/-$ \\
\hline Islander et al. & 2010 & Mouse & Yes & $\sim 5 \mathrm{mg} / \mathrm{kg}$ & $\sim 25 \mathrm{~d}$ & Daily, i.p. & + \\
\hline $\begin{array}{c}\text { Rauchhaus } \\
\text { et al. }\end{array}$ & 2009 & Mouse & Yes & $0.4-4 \mathrm{mg} / \mathrm{kg}$ & $7 \mathrm{~d}$ & Once, i.v. & $+/-$ \\
\hline Wang et al. & $2017 \mathrm{a}$ & Rat & Yes & $0.15 \mathrm{mg} / \mathrm{kg}$ & $7 \mathrm{~d}$ & Daily, oral gavage & + \\
\hline Malfait et al. & 2009 & Rat & Yes & $\begin{array}{c}1 \mathrm{mg} / \mathrm{kg} \text { or } \\
0.001-1 \mathrm{mg} / \mathrm{mL}\end{array}$ & $16 \mathrm{~h}$ & $\begin{array}{c}\text { Once, oral gavage } \\
\text { or i.v. infusion }\end{array}$ & + \\
\hline Ashraf et al. & 2011 & Rat & Yes & $0.1 \mathrm{mg} / \mathrm{kg}$ & $24 \mathrm{~d}$ & Daily, oral gavage & + \\
\hline Jaffré et al. & 2003 & Rat & Yes & $0.1 \mathrm{mg} / \mathrm{kg}$ & $5-21 d$ & Daily, i.a. & $+/-$ \\
\hline $\begin{array}{l}\text { Annefeld and } \\
\text { Erne } \\
\end{array}$ & 1987 & Rat & No & $3 \mathrm{mg} / \mathrm{kg}$ & 3 weeks & 1/week, i.m. & - \\
\hline $\begin{array}{c}\text { Podbielski } \\
\text { and Raiss }\end{array}$ & 1985 & Rat & No & $3.3 \mathrm{mg} / \mathrm{kg}$ & 3-5 weeks & 1/week, i.m. & - \\
\hline Glade et al. & 1983 & Horse & No & $0.005 \mathrm{mg} / \mathrm{kg}$ & 3-11 months & Daily, i.m. & - \\
\hline
\end{tabular}

including hypertension, adrenal gland depression, psychological disturbances, Cushing's syndrome, osteoporosis and susceptibility to infections as a result of immunosuppression (Bordag et al., 2015; Manson et al., 2009).

The present narrative review presents literature on DEX effects in both arthritic and healthy model systems. The potential disease-modifying and catabolic effects of DEX are described and the need for dose-duration studies in humans are emphasised to ascertain under what conditions DEX may be safe to use and whether it may have uses as a DMOAD in treating OA beyond analgesia and reducing inflammation. A search for "dexamethasone effects on cartilage" in PubMed and Cochrane Library databases returned 451 results, 46 of which were selected for their relevance to the scope of the review. Criteria for inclusion were: (1) use of DEX alone (i.e. not in combination with another drug or with a method of delivery that could affect the distinction between the effects of DEX or the effects of a carrier) and (2) use of either an animal model (i.e. measuring changes to cartilage and OA scores), cartilage explants or chondrocytes, whether primary or derived from a chondrogenic line.

\section{DEX and animal models of arthritis}

Studies in animals (Table 1) have suggested a promising role for DEX as a potent preventative measure against arthritis progression but, conversely, suggest that it may damage healthy cartilage at certain doses and durations. In a collagen-induced mouse model of RA, Rauchhaus et al. (2009) found that daily intravenous injections of free $1.6 \mathrm{mg} / \mathrm{kg}$ DEX or a single injection of $0.4-4 \mathrm{mg} / \mathrm{kg}$ liposomalencapsulated DEX both reduce the frequency of arthritis occurrence and lower its severity. However, the persistent anti-inflammatory effects gained by single-dose liposomal encapsulation hinted at the importance of drug delivery. Islander et al. (2011) used a mouse postmenopausal OA model and found that daily $125 \mu \mathrm{g}$ intraperitoneal injections of DEX protect against arthritis and joint destruction. A rat meniscal transection OA model showed that daily oral gavage treatments with $0.1 \mathrm{mg} / \mathrm{kg}$ DEX starting $11 \mathrm{~d}$ after surgery decrease animal pain response in the affected paw, lowers inflammation and macrophage infiltration and partially rescues PG loss in the joint cartilage (Ashraf et al., 2011). Another similar rat study using an AA model treated with $0.15 \mathrm{mg} / \mathrm{kg}$ daily DEX through oral gavage starting $13 \mathrm{~d}$ after AA induction found less swelling in the paws of rats treated with DEX. The same study showed that there is also a significant overlap in genes downstream of inflammatory mediators regulated by DEX and the network of genes affected by the development of AA but did not explore the identity of these genes or how they may provide protection to cartilage (Wang et al., 2017a). Rabbits injected i.a. with $0.5 \mathrm{mg} / \mathrm{kg}$ DEX once before and every $3 \mathrm{~d}$ after a surgery-induced PTOA showed protection of articular cartilage at 3 weeks after surgery, with Mankin scores equal to the control rabbits (Huebner et al., 2014). Heard et al. (2015) used the same rabbit surgical model, with 
a single i.a. DEX injection at the time of surgery $(0.5 \mathrm{mg} / \mathrm{kg})$, and showed significant improvement of histological grading of cartilage and synovium 9 weeks post-surgery. This is due to improvement in safranin-O staining of GAGs, while DEX treatment does not influence the medial structure grade. Malfait et al. (2009) credited such a protective effect of DEX on inhibition of GAG loss to protection against aggrecan proteolysis in the cartilage matrix, as demonstrated in their rat model of OA using i.a. injections of TNF $\alpha$ followed by $16 \mathrm{~h}$ of intravenous infusion with 0.001 $1 \mathrm{mg} / \mathrm{mL}$ DEX in saline.

The most in-depth analysis of cartilage structure after DEX treatment in an animal model was performed by Jaffré et al. (2003), who used quantitative ultrasound measurements and picrosirius red staining to study the surface and internal structure of cartilage after inducing synovitis and significant loss of cartilage sGAG in rats with injections of zymosan. Daily i.a. injections of $0.1 \mathrm{mg} / \mathrm{kg}$ DEX prevent knee swelling and histological changes such as loss of hypertrophic cells and surface alterations, seen by toluidine blue staining, and maintain PG content at control levels. Using ultrasound measurements, they demonstrated that DEX returns the integrated reflection coefficient of the OA-challenged cartilage to control levels after $14 \mathrm{~d}$, suggesting that DEX restores the microarchitecture and smoothness of the superficial layer after zymosan challenge. However, after 2 weeks of DEX treatment, the internal collagen network of the cartilage is markedly changed, with thinner and more disperse collagen fibres, a greater change than the effect of arthritis induction alone.

While DEX appears to provide protection against cartilage degradation, the results of Jaffré et al. suggest that there may be some dysregulation of the internal structure of cartilage organisation. It is also important to note the degenerative side effects of long-term daily DEX treatment: extended high doses of DEX can retard growth, which was verified by Jaffré et al. (2003) with significantly lower knee sizes and weights in DEX-treated rats. The rabbits in the study by Huebner et al. (2014) had extensive damage to their organs after DEX treatment: lungs, livers and kidneys appeared fibrotic and had large necrotic areas, suggesting serious systemic side effects to drug treatment. Rauchhaus et al. (2009) reported other systemic side effects in their mouse model, with reductions in body weight and lymphocyte count, neutrophilia and transient reduction in serum corticosterone levels. Two injections of 0.12 or $0.24 \mathrm{mg}$ DEX reduce the growth of rat foetuses (an unsurprising finding given the well-established effect of GCs stunting growth in developing children) and cause the cartilage within the foetuses to have lower collagen content and reduced chondrocyte biosynthetic activity (Dearden et al., 1986; Mushtaq and Ahmed, 2002). Taken together, these findings suggest the need for new approaches to deliver sustained low-doses of GCs intra-cartilage through single injection, thereby minimising unwanted exposure of other tissues (see Discussion; Krishnan et al., 2018).

\section{DEX and healthy, non-arthritic animal models}

Results from animal models have demonstrated that there is clearly a need to better understand the appropriate dosage and duration of treatment to prevent local and systemic side effects, especially when considering how the potential detrimental effects of DEX can extend to healthy cartilage. In models of OA, DEX can maintain the PG content of cartilage, but in healthy animals, DEX has been shown to damage cartilage and chondrocytes depending on dose and frequency of treatment. In a long-term study by Glade et al. (1983), daily intra-muscular injections of $0.5-5.0 \mathrm{mg} / 100 \mathrm{~kg}$ DEX into 6-month-old pony weanlings for up to 11 months caused massive degeneration of the still-developing injected joints, with articular lesions, fibrous scars and large necrotic areas in both cartilage and bone. These results were attributed to a depression of cartilage metabolism during the first 8 months of treatment, measured by ${ }^{35} \mathrm{~S}$-methionine incorporation and LDH activity. In a small animal model but with a much higher DEX-dose, rats treated with $3.33 \mathrm{mg} / \mathrm{kg}$ DEX by systemic intramuscular injection for 5 weeks $(1 \mathrm{mg} /$ week) showed reduced size of the rough endoplasmic reticulum and Golgi complex within articular chondrocytes, hypothesised to cause a reduction in protein synthesis (Podbielski and Raiss, 1985). DEX treatment resulted in an increased number of dead cells, attributed to its effect on lysosomal function as well as disrupting cell metabolism through reducing mitochondrial size. Annefeld and Erne (1987) also found a suppression of cartilage metabolism with a similar dose of intramuscular DEX (3 mg/kg), as well as higher rates of cell death within the cartilage after only 3 weeks. While it is difficult to extrapolate the doses used in animal models to what is appropriate for human patients, it is apparent that in some ways the effects of DEX may be chondroprotective under arthritic stresses but lead to catabolic degeneration and loss of viability in healthy tissue as dose and duration increase.

Using animal models, chondrocyte death and matrix degradation are two of the most commonly reported outcome measures for determining the beneficial or harmful effects of DEX. However, there are many processes affecting these readouts that these studies do not always capture: DEX regulates many intracellular processes affecting cell viability and regulates both production of ECM proteins as well as proteases responsible for organising and breaking down the matrix. Some of the most well-studied processes are summarised in Fig. 1. The complex nature of the interactions between these effects complicates the interpretation of DEX effect on cartilage tissue and necessitates using in vitro cartilage explant and chondrocyte studies to interrogate the mechanistic effects of DEX. 
Table 2. DEX studies using explants from human or animal cartilage in models of arthritis. Summary of DEX concentration, duration of culture, inflammatory cytokines used to model arthritic conditions and observed effect on measurements associated with arthritis progression. APC: activated protein C. + indicates a rescue of arthritis-induced effects, +/= rescue of only some effects and +/- rescue of some effects and worsening of others. Wang et al. (2014) Dexamethasone treatment alters the response of human cartilage explants to inflammatory cytokines and mechanical injury as revealed by discovery proteomics. Osteoarthritis Cartilage 25: S381-S382.

\begin{tabular}{|c|c|c|c|c|c|c|}
\hline Authors & Year & $\begin{array}{c}\text { Tissue } \\
\text { type }\end{array}$ & Cytokine treatment & DEX dose & Duration & $\begin{array}{c}\text { Observed } \\
\text { effect }\end{array}$ \\
\hline \multirow{2}{*}{ Li et al. } & \multirow{2}{*}{2015} & Human & $1 \mathrm{ng} / \mathrm{mL} \mathrm{IL-1} \alpha$ & $100 \mathrm{nM}$ & $24 \mathrm{~d}$ & + \\
\hline & & Bovine & $1 \mathrm{ng} / \mathrm{mL}$ IL-1 $\alpha$ & $100 \mathrm{nM}$ & $24 \mathrm{~d}$ & $+/=$ \\
\hline Wang et al. & 2014 & Human & $\begin{array}{l}100 \mathrm{ng} / \mathrm{mL} \text { TNF } \alpha \\
+50 \mathrm{ng} / \mathrm{mL} \mathrm{IL-6}\end{array}$ & $100 \mathrm{nM}$ & $21 \mathrm{~d}$ & + \\
\hline \multirow{2}{*}{ Lu et al. } & \multirow{2}{*}{2011} & Human & $\begin{array}{c}100 \mathrm{ng} / \mathrm{mL} \text { TNF } \alpha \\
\pm 50 \mathrm{ng} / \mathrm{mL} \mathrm{IL-6}\end{array}$ & $10 \mathrm{nM}$ & $6 \mathrm{~d}$ & + \\
\hline & & Bovine & $\begin{array}{l}25 \mathrm{ng} / \mathrm{mL} \text { TNF } \alpha \\
\pm 50 \mathrm{ng} / \mathrm{mL} \mathrm{IL-6}\end{array}$ & $10 \mathrm{nM}$ & $6 \mathrm{~d}$ & + \\
\hline Busschers et al. & 2010 & Equine & $5 \mathrm{ng} / \mathrm{mL} \mathrm{IL}-1 \beta$ & $100 \mathrm{nM}-1 \mu \mathrm{M}$ & $72 \mathrm{~h}$ & $+/=$ \\
\hline Garvican et al. & 2010 & Equine & $\begin{array}{c}10 \mathrm{ng} / \mathrm{mL} \mathrm{IL-1} \\
+10 \mu \mathrm{g} / \mathrm{mL} \mathrm{APC}\end{array}$ & $1-100 \mu \mathrm{M}$ & $4 \mathrm{~d}$ & $+/-$ \\
\hline Saito et al. & 1999 & Rabbit & $\begin{array}{c}1 \mathrm{ng} / \mathrm{mL} \text { IL-1 } \alpha \\
+100 \mu \mathrm{g} / \mathrm{mL} \\
\text { plasminogen }\end{array}$ & $0.1-100 \mathrm{nM}$ & $7 \mathrm{~d}$ & + \\
\hline
\end{tabular}

\section{Cartilage explant models of arthritis}

While there are no clinical data on the specific effects of DEX on cartilage in human patients, several studies have been performed on cartilage explants in vitro using tissue from human donors (Table 2). Li et al. (2015) demonstrated in an IL- $1 \alpha$-challenge of fullthickness near-normal human cartilage disks that culture with $100 \mathrm{nM}$ DEX continuously over a $17 \mathrm{~d}$ treatment rescues GAG loss and maintains more viable cells within the cartilage, relevant to potential PTOA prevention. DEX also rescues the cytokineinduced decrease in sGAG synthesis, although not up to control levels. These results showed the beneficial effects of DEX to cartilage metabolism and ECM synthesis in a diseased state, the opposite of what is seen following long-term DEX treatment of healthy developing animal models (Glade et al., 1983). Using human tissue in an $8 \mathrm{~d}$ TNF $\alpha+$ IL- 6 challenge of normal human knee explants $( \pm$ a single compressive impact injury relevant to PTOA), Lu et al. (2011) also found that continuous DEX treatment prevents GAG loss. Interestingly, in the same TNF $\alpha /$ IL-6 model, DEX greatly decreases the secreted levels of MMP-1 and -13 , which correlates with decreases in fragments of ECM components released into the media, such as aggrecan, cartilage oligomeric matrix protein and collagen III neoepitopes [Wang et al. (2014) Dexamethasone treatment alters the response of human cartilage explants to inflammatory cytokines and mechanical injury as revealed by discovery proteomics. Osteoarthritis Cartilage 25: S381-S382].
Animal cartilage explant models corroborate some of the findings of human tissue and offer some additional mechanistic understanding of how the effects of DEX on arthritis progression are propagated at the transcriptional level. DEX returns GAG loss and sulphate incorporation to control levels in $\mathrm{TNF} \alpha$ treated bovine cartilage at DEX concentrations as low as $1 \mathrm{nM}$ (Lu et al., 2011). The reduction in GAG loss was suggested to be due to a suppressive effect of DEX on the activity of remodelling proteases, such as aggrecanases, through routes not limited to transcription alone, particularly in the case of ADAMTS-4 and -5, where mRNA transcripts remained elevated even after DEX exposure. A similar finding was reported by Busschers et al. (2010) using equine cartilage, where the addition of $100 \mathrm{nM}$ or $1 \mu \mathrm{M}$ DEX does not reduce the increase in ADAMTS-5 transcription after IL- $1 \beta$ challenge and levels of ADAMTS-4 mRNA transcripts are still elevated as compared to control, although decreased as compared to IL-1 $\beta$ alone. The same study reported no change in GAG loss into the medium or GAG content of articular and nasal cartilage explants after $72 \mathrm{~h}$ of exposure to DEX, differently from the findings of Lu et al. (2011) with bovine cartilage and from studies using human cartilage. Whether this is due to a difference in species, inflammatory cytokines used to model arthritis or culture length remains to be answered.

Li et al. (2015), in a $24 \mathrm{~d}$ IL-1 $\alpha$-challenge of bovine cartilage explants, observed that DEX maintains 
cell viability as measured by fluorescein diacetate and propidium iodide staining, consistent with a previous report of rescue of cell viability following mechanical impact injury using $100 \mu \mathrm{M} \mathrm{DEX}\left(\mathrm{D}^{\prime}\right.$ Lima et al., 2001). PCR results showed that after $4 \mathrm{~d}$ of IL-1 $\alpha$ treatment, DEX greatly decreases the transcription of IL-6, ADAMTS-4, ADAMTS-5, MMP-3 and MMP-13 as compared to IL- $1 \alpha$ alone without DEX, while also rescuing some expression of aggrecan and collagen II, although not up to control levels (Li et al., 2015). It is of note that these results contradict the findings of Lu et al. (2011) on the effect of DEX on ADAMTS-4 and -5 transcription, although this discrepancy may be due to the different inflammatory cytokines used to stimulate cartilage breakdown and subsequent transcriptional pathways being activated. In another experiment with IL-1 $\alpha$ and plasminogen challenge on rabbit cartilage, Saito et al. (1999) also found a decrease in the release of MMP-1 and - 3 into the culture media at DEX concentrations as low as $1 \mathrm{nM}$. In addition, they showed some rescue of hydroxyproline release, a marker of collagen degradation.

Taken together, these results support the hypothesis that DEX helps to prevent the degradation of ECM components by inhibiting the increase in transcription or activity of matrix-degrading factors brought on during the progression of arthritis and by restoring some level of expression of the matrix components themselves (Fig. 1). However, there are still some discrepancies among the results of these experiments. While Li et al. (2015) reported a decrease in IL-6 expression in IL- $1 \alpha$-challenged bovine explants, Lu et al. (2011) did not see a change in IL-6 transcription with the addition of DEX to TNF $\alpha$-challenged tissue. Garvican et al. (2010), using equine cartilage explants subjected to treatment

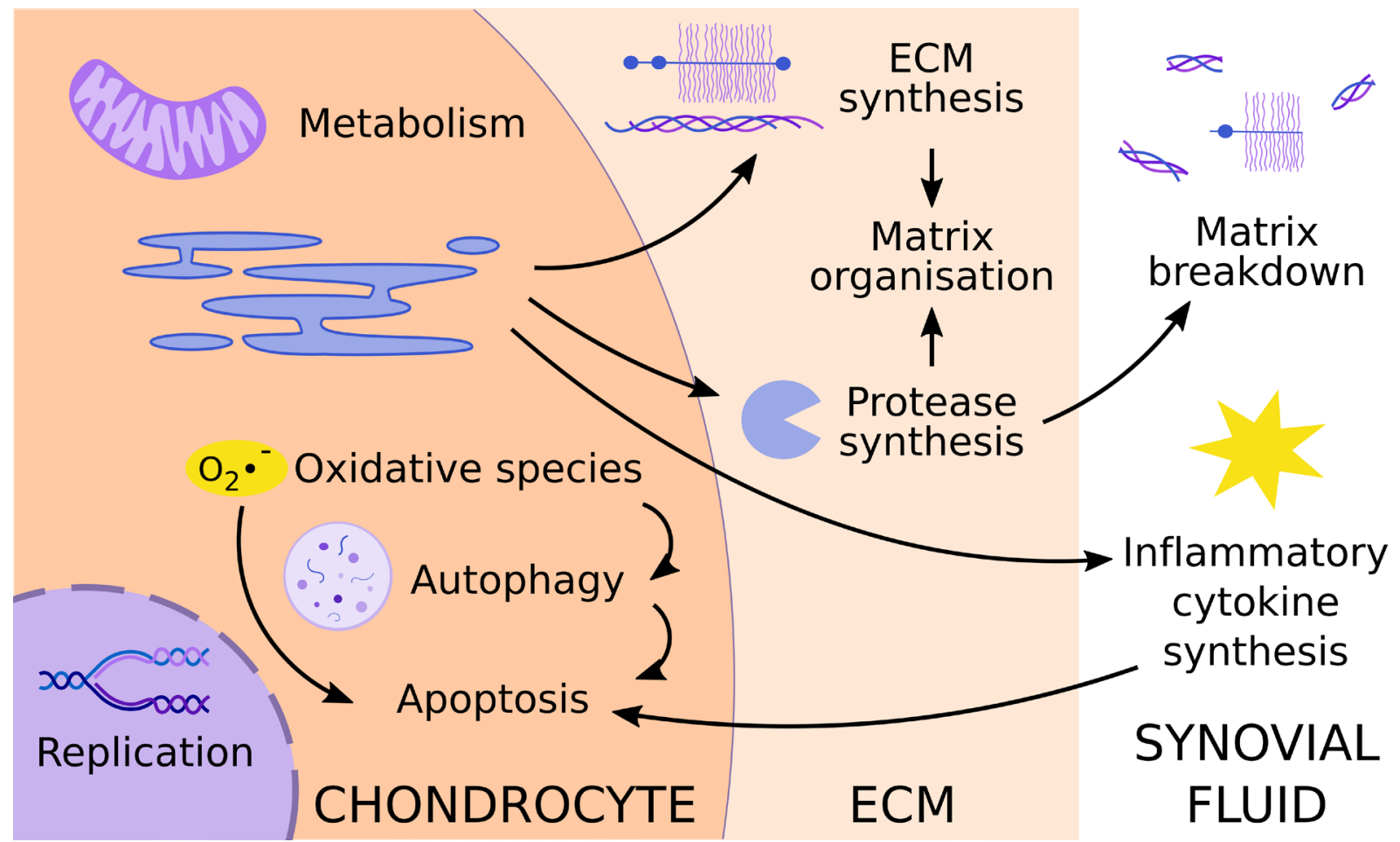

Fig. 1. Biological processes identified as being affected by DEX either in healthy or diseased cartilage in studies using in vivo models, cartilage explants or chondrocyte monoculture. DEX affects matrix organisation at the level of both ECM and protease synthesis, although studies often disagree on the specific up- or downregulation of ECM specific components. There is a consensus that, under arthritic stresses, DEX prevents the upregulation of protease synthesis, which can prevent matrix loss. However, at higher doses, in healthy cartilage, DEX may increase the rate of matrix degradation or the organisation of the matrix itself. This could be due to effects on matrix components and proteases or due to intracellular effects on metabolism and the production of ROS that activate autophagy and lead to significant cell death. Data from in vitro studies have suggested that DEX maintains cell viability under arthritic stress, which could be linked to a DEX-induced reduction in inflammatory cytokine synthesis. Alternatively, the metabolic processes that DEX dysregulates in healthy tissue could serve to rescue changes in those processes after the initiation of arthritis. While the induction of autophagy in healthy tissue could lead to chondrocyte death and subsequent matrix breakdown, autophagy is suppressed in arthritic contexts, so DEX could serve to rescue these cellular processes in a diseased state. It remains to be seen whether DEX inhibits proliferation under arthritic stress and what role this might play in disease progression and whether the phenomenon of DEX-induced reduction of proliferation in healthy cartilage is due to cells becoming quiescent or senescent. Each possibility would have a significantly different biological outcome on cartilage exposed to DEX for an extended time. 
Table 3. DEX studies using cartilage explants in non-arthritic model systems. Summary of DEX concentration, duration of culture and overall observed effect on cartilage. $=$ indicates no change in measured outcomes, + /= some healthy effects and some outcomes that do not change and - adverse effects on the cartilage tissue.

\begin{tabular}{|c|c|c|c|c|c|}
\hline Authors & Year & Tissue type & DEX dose & Duration & Observed effect \\
\hline Siengdee et al. & 2015 & Porcine & $1.25-5 \mathrm{mM}$ & 2 weeks & - \\
\hline Lu et al. & 2011 & Bovine & $10 \mathrm{nM}$ & $6 \mathrm{~d}$ & $=$ \\
\hline Bian et al. & 2010 & Bovine & $0.1 \mu \mathrm{M}$ & 4 weeks & $+/=$ \\
\hline Busschers et al. & 2010 & Equine & $100 \mathrm{nM}-1 \mu \mathrm{M}$ & $72 \mathrm{~h}$ & - \\
\hline Datuin et al. & 2001 & Tilapia & $0.25 \mathrm{nM}-2.5 \mu \mathrm{M}$ & Not reported & - \\
\hline
\end{tabular}

with IL- 1 and APC, observed that $1 \mu \mathrm{M}$ DEX rescues hydroxyproline loss and decreases MMP-1, -3 and -13 transcription. However, DEX + APC treatment increases GAG release above the levels of IL-1/APC alone. This discrepancy may be due to the combined treatment with a protease as opposed to cytokines alone, as in the other models. Alternatively, GAG loss may be overestimated due to the analysis being based on GAG loss per wet weight of cartilage, a calculation that yields an exponentially increasing result for a linearly increasing loss of GAG.

\section{Non-arthritic cartilage explant models}

Experiments treating healthy cartilage with DEX in the absence of an arthritic context have shown disagreements in the effects of DEX on ECM composition and tissue metabolism (Table 3). Two separate experiments with normal juvenile bovine explants treated with $100 \mathrm{nM}$ DEX and one with equine cartilage explants treated with $100 \mathrm{nM}$ or $1 \mu \mathrm{M}$ DEX showed no change in the concentration of GAG per wet weight of the explants. The two bovine experiments reported no change in the release of GAGs into the culture medium (Bian et al., 2010; Lu et al., 2011), while equine cartilage explants showed a slight increase in GAG loss and a corresponding increase in the protease ADAMTS-5 transcript levels (Busschers et al., 2010). However, Siengdee et al. (2015) found that a dose of $1.27 \mathrm{mM}$ DEX, four orders of magnitude larger than that used by the three previously mentioned studies, causes porcine cartilage explants to release less GAG content into the culture medium and to maintain higher levels of safranin-O staining, indicative of larger concentrations of GAGs in the cartilage matrix.

The effect of DEX on the structure of the cartilage matrix may be dependent on the developmental state of the tissue, as Bian et al. (2010) observed an increase in equilibrium modulus and dynamic modulus of DEX-treated juvenile bovine cartilage, but not in adult bovine or canine cartilage, an effect that may be due to DEX causing more rapid differentiation of immature chondrocytes and subsequent changes to the ECM. In the same experiment, treated juvenile explants had higher concentrations of orthohydroxyproline (analogous to total collagen concentration) per wet weight after DEX exposure, while adult explants did not.

How the metabolism of healthy cartilage responds to DEX exposure is also unclear. Lu et al. (2011) showed no change in the rate of ${ }^{35} \mathrm{~S}$-sulphate incorporation at low doses of DEX; only at doses above $100 \mathrm{nM}$, ${ }^{35} \mathrm{~S}$-sulphate incorporation significantly increases as compared to the control. However, Datuin et al. (2001) observed the exact opposite effect in a tilapia gill cartilage explant model, where any exposure to DEX, as low as $250 \mathrm{pM}$, significantly decreases the level of ${ }^{35} \mathrm{~S}$-sulphate uptake, suggesting a decrease in metabolic activity and ECM synthesis. Due to the variety of transcriptional changes caused by GCs, it is unsurprising that there would be effects on the rates of protein synthesis within the tissue, even if the direction of the effect reported in the literature is inconsistent, perhaps across different species or types of cartilage used. Siengdee et al. (2015) hypothesised that DEX treatment would lead to some level of cell death within the matrix, as confirmed by histological sections revealing clusters of clumped chondrocytes, indicative of cell death. While Datuin et al. (2001) did not report effects on cell viability within the tissue, DEX doses above $250 \mathrm{nM}$ significantly decrease the level of ${ }^{3} \mathrm{H}$-thymidine incorporation, associated with decreased cell proliferation.

Cartilage explant models of arthritis show potentially protective effects of DEX on ECM due to the downregulation of MMPs. In addition, the structure of healthy cartilage seems to be maintained under DEX exposure. However, the results on cell behaviour and metabolism within native tissue leave open the possibility that there may be negative effects of the drug on resident chondrocytes, especially at higher doses. Several studies have been performed on chondrocytes isolated from tissue to interrogate the mechanisms of DEX action in both arthritic and healthy contexts, with many conflicting results in different models and DEX doses, as described below.

\section{DEX and chondrocyte studies of arthritis and inflammation}

Human chondrocytes isolated from patients with arthritis or cultured with inflammatory cytokines offer a model system in which the pathways affected by 
Table 4. DEX studies using chondrocytes isolated from arthritic patients and/or cultured with inflammatory cytokines. Summary of cell source (OA: from patient with symptomatic OA), inflammatory cytokines used to model arthritic conditions, DEX concentration and duration of culture. N/A: not available. Wang et al. (2017b) Phosphoproteomics analysis of signaling changes in human chondrocytes following treatment with Il-1, IGF-1 and dexamethasone. Osteoarthritis Cartilage 25: S165-S166.

\begin{tabular}{|c|c|c|c|c|c|}
\hline Authors & Year & Cell type & Cytokine treatment & DEX dose & Duration \\
\hline Wang et al. & $2017 \mathrm{~b}$ & Human & $10 \mathrm{ng} / \mathrm{mL} \mathrm{IL-1} \alpha$ & $100 \mathrm{nM}$ & $30 \mathrm{~min}$ \\
\hline Tu et al. & 2013 & Human, OA & N/A & $63 \mu \mathrm{M}$ & $48 \mathrm{~h}$ \\
\hline Stöve et al. & 2002 & Human, OA & $0.1 \mathrm{ng} / \mathrm{mL} \mathrm{IL-1 \beta}$ & $100 \mathrm{nM}-10 \mu \mathrm{M}$ & 1 week \\
\hline $\begin{array}{c}\text { Palmer } \text { et al. } \\
\text { et al. }\end{array}$ & 2002 & Human, OA & $\begin{array}{c}10 \mathrm{ng} / \mathrm{mL} \mathrm{IL-1} \beta \text { or } \\
100 \mathrm{ng} / \mathrm{mL} \mathrm{IL-6}\end{array}$ & $100 \mathrm{nM}$ & $18 \mathrm{~h}$ \\
\hline $\begin{array}{c}\text { Shalom-Barak } \\
\text { Villiger } \text { et al. }\end{array}$ & 1998 & Human & $10 \mathrm{ng} / \mathrm{mL} \mathrm{IL-17}$ & $1-100 \mathrm{nM}$ & $48 \mathrm{~h}$ \\
\hline $\begin{array}{c}\text { Roach } \text { et al. } \\
\text { Busschers } \text { et al. }\end{array}$ & 2016 & Hovine & $10 \mathrm{ng} / \mathrm{mL} \mathrm{IL-1} \alpha$ & $100 \mathrm{nM}$ & $35 \mathrm{~d}$ \\
\hline $\begin{array}{c}\text { Richardson } \\
\text { and Dodge }\end{array}$ & 2003 & Equine & $5 \mathrm{ng} / \mathrm{mL} \mathrm{IL-1 \beta}$ & $100 \mathrm{nM}-1 \mu \mathrm{h}$ & $24 \mathrm{~h}$ \\
\hline $\begin{array}{c}\text { Sadowski and } \\
\text { Steinmeyer }\end{array}$ & 2001 & Borse & $\begin{array}{c}10 \mathrm{ng} / \mathrm{mL} \mathrm{IL-1} \beta \text { or } \\
25 \mathrm{ng} / \mathrm{mL} \mathrm{TNF} \alpha\end{array}$ & $10 \mathrm{nM}-1 \mu \mathrm{nM}$ & $24 \mathrm{~h}$ \\
\hline
\end{tabular}

DEX treatment can be examined in more detail (Table 4). However, in keeping with the animal and explant studies, it is difficult to draw specific conclusions because publications often report conflicting results. Stöve et al. (2002) isolated primary chondrocytes from the cartilage of OA patients taken at the time of knee joint replacement surgery and cultured them in alginate beads with $0.1 \mathrm{ng} / \mathrm{mL}$ IL-1 $\beta$. They found that the addition of DEX $(100 \mathrm{nM}-10 \mu \mathrm{M})$ lowers the PG content of the culture and decreases the transcription of aggrecan and MMP-3, supporting the hypothesis that DEX does not protect cartilage by increasing the synthesis of ECM components but instead by preventing the synthesis of matrix-degrading factors. Villiger et al. (1992), using chondrocytes and cartilage from human donors with no joint disease, showed that culture with IL-1 stimulates increased transcription of biologically active MCP-1, while treatment with DEX decreases MCP-1 synthesis, suggesting the ability to prevent monocyte infiltration and, thus, progression of cartilage degradation. However, certain chondrocyte models reveal that DEX may pose a risk to cell viability. For example, $63 \mu \mathrm{M}$ DEX was shown to significantly increase the rate of apoptosis in chondrocytes isolated from knee cartilage of OA joint replacement patients by decreasing ERK signalling (Tu et al., 2013). This DEX dose was quite high, but other examples in the literature discussed below show similar effects at doses orders of magnitude lower.

Some studies with human chondrocytes have been performed to elucidate the effect of DEX on inflammatory pathways, although the entire picture remains unclear. 1-100 nM DEX reduces IL-17induced NO synthesis, inhibiting the production of IL-6 and iNOS transcription, suggesting a potential pathway for the anti-inflammatory effects of DEX in cartilage tissue (Shalom-Barak et al., 1998). $100 \mathrm{nM}$ DEX decreases the transcription of IL-1Ra after IL-6 exposure with human primary chondrocytes, indicating that IL-1Ra production is not a method by which DEX could protect cartilage against damaging inflammatory factors (Palmer et al., 2002). A phosphoproteomics study using primary human chondrocytes treated with IL- $1 \alpha$ and $100 \mathrm{nM}$ DEX showed a decrease in the phosphorylation of JNK1 and -2 linked to the anti-catabolic effects of DEX, suggesting a major role for JNKs in regulating cartilage breakdown upon inflammatory challenge [Wang et al. (2017b) Phosphoproteomics analysis of signaling changes in human chondrocytes following treatment with Il-1, IGF-1 and dexamethasone. Osteoarthritis Cartilage 25: S165-S166].

Several studies of animal chondrocytes subjected to arthritic-like conditions (Table 4) are consistent with some of the findings from human cells. IL-1 $\alpha$ or $\beta$-challenged chondrocytes from equine and bovine joint cartilage also show decreased expression levels of MMP-3, -13 and -1 when treated with $100 \mathrm{nM}$ DEX (Busschers et al., 2010; Richardson and Dodge, 2003; Sadowski and Steinmeyer, 2001). However, DEX has similar effects on the family of TIMPs, decreasing their expression levels, further supporting the hypothesis that DEX may cause dysregulation of matrix organisation beyond the scope of MMPs alone. This dose of DEX does not rescue GAG loss in 
Table 5. Results on cell viability and proliferation after DEX treatment on primary chondrocytes in non-arthritic model systems. - denotes a decrease and = no change from control.

\begin{tabular}{|c|c|c|c|c|c|}
\hline Authors & Year & Cell type & DEX dose & Duration & $\begin{array}{c}\text { Effect on } \\
\text { viability }\end{array}$ \\
\hline Shen et al. & 2015 & Human & $1 \mu \mathrm{M}, 10 \mu \mathrm{M}$ & $24 \mathrm{~h}$ & - \\
\hline Liu et al. & 2014 & Human & $100 \mu \mathrm{M}$ & $72 \mathrm{~h}$ & - \\
\hline Stueber et al. & 2014 & Human & $10 \mu \mathrm{M}-1 \mathrm{mM}$ & $1 \mathrm{~h}$ & $=$ \\
\hline Zaman et al. & 2014 & Human & $1 \mu \mathrm{M}$ & $24-72 \mathrm{~h}$ & - \\
\hline Song et al. & 2012 & Human & $20-200 \mu \mathrm{M}$ & $24 \mathrm{~h}-1$ week & - \\
\hline Dragoo et al. & 2012 & Human & $1.5 \mathrm{mM}$ & 1 week & $=$ \\
\hline Authors & Year & Cell type & DEX dose & Duration & $\begin{array}{c}\text { Effect on } \\
\text { proliferation }\end{array}$ \\
\hline Mushtaq et al. & 2002 & Mouse & $10 \mathrm{nM}-1 \mu \mathrm{M}$ & $20 \mathrm{~d}$ & - \\
\hline Miyazaki et al. & 2000 & Rat & $0.1 \mathrm{nM}-100 \mu \mathrm{M}$ & $36 \mathrm{~h}$ & - \\
\hline Hainque et al. & 1987 & Rabbit & $10 \mathrm{nM}-100 \mu \mathrm{M}$ & $24 \mathrm{~h}-2$ weeks & - \\
\hline Maor and Silbermann & 1986 & Mouse & $1 \mu \mathrm{M}$ & $24 \mathrm{~h}$ & - \\
\hline
\end{tabular}

response to IL-1 $\beta$ stimulation of equine chondrocytes (Richardson and Dodge, 2003) but rescues collagen II loss in a model using IL- $1 \alpha$-challenged bovine chondrocytes cultured in agarose gels (Roach et al., 2016). Similar to the results of Glade et al. (1983) and Datuin et al. (2001), Sadowski and Steinmeyer (2001) found that DEX treatment (100 nM to $50 \mu \mathrm{M})$ depresses total protein synthesis by up to $40 \%$ in bovine chondrocytes stimulated with IL- $1 \alpha$, although cell viability is not affected by DEX. Roach et al. (2016) also reported that DEX does not change the anti-proliferative effect of IL- $1 \alpha$ treatment and that treating the chondrocytes with DEX alone results in the same inhibition of proliferation as inflammatory cytokines.

DEX has also been demonstrated to regulate the transcription of COX2, an inflammation-induced enzyme that produces prostaglandins, in arthritic contexts. $100 \mathrm{nM}$ DEX prevents the transcription of COX2 in primary human chondrocytes after IL-1 $\beta$ exposure, as well as the production of prostaglandin E2, a (mostly) pro-inflammatory agent that has been a palliative target for RA treatment for years (Geng et al., 1995; McCoy et al., 2002; Sheibanie et al., 2007). However, inhibition of COX2 likely does not produce a straightforward anti-inflammatory response, as some prostaglandins produced by COX2 can have anti-inflammatory effects and even prostaglandin $\mathrm{E} 2$ is involved in the resolution of inflammation as well as its induction in an RA mouse model (Chan and Moore, 2010).

\section{Non-arthritic chondrocyte cultures: effects on viability and proliferation}

Most studies with human chondrocytes show an apoptotic effect of DEX on isolated cells in a nonarthritic context (Liu et al., 2014; Shen et al., 2015;
Zaman et al., 2014), which Liu et al. (2014) attributed to the induction of autophagy by DEX (Table 5). In their model, a downstream effect of DEX is to increase the production of ROS, which trigger an autophagic response, leading to cell death. However, Shen et al. (2015) proposed that oxidative stress due to increased ROS production is the cause of chondrocyte death and that autophagy serves to protect cells from this stress. This discrepancy could be due to the difference in DEX concentration used, which was two orders of magnitude higher in Liu et al. (2014) than Shen et al. (2015), but the complex interplays between these pathways, highlighted in Fig. 1, remain to be clarified.

In contrast to these studies, Dragoo et al. (2012) did not find any change in the amount of cell death, even at the incredibly high dose of $1.5 \mathrm{mM}$ DEX. Stueber et al. (2014) reported no change in cell viability as well, although their experiment only tested the effects of the drug for $1 \mathrm{~h}$, while Song et al. (2012) reported viability changes only after $72 \mathrm{~h}$ of treatment. However, Dragoo et al. (2012) reported their results after 1 week of treatment, so the discrepancy with that experiment remains.

Mushtaq et al. (2002) were the only group using isolated animal chondrocytes that reported the effects of DEX on apoptosis and found no change after $20 \mathrm{~d}$ of DEX treatment. It is of note that these cells were a chondrogenic teratocarcinoma cell line instead of primary chondrocytes, which may have influenced their behaviour. However, all three groups that have used animal chondrocytes reported a reduction in the rate of cell proliferation after DEX exposure, suggesting that even if DEX does not kill the cells, it makes them more quiescent (Hainque et al., 1987; Maor and Silbermann, 1986; Miyazaki et al., 2000). It is unclear why so many chondrocyte models report an apoptotic effect that is not reflected in tissue 
Table 6. ECM-related gene expression of primary chondrocytes after DEX exposure. + denotes an increase, - a decrease and = no change from control. James et al. (2007) used an ECM gene set from the Gene Set Enrichment Analysis (GSEA) database (Subramanian et al., 2005).

\begin{tabular}{|c|c|c|c|c|c|}
\hline Authors & Year & Cell type & DEX dose & Duration & Effect on RNA expression \\
\hline Song et al. & 2012 & Human & $20-200 \mu \mathrm{M}$ & $24 \mathrm{~h}-1$ week & - ACAN, - collagen II \\
\hline James et al. & 2007 & Mouse & $100 \mathrm{nM}$ & $24 \mathrm{~h}$ & + ECM genes \\
\hline $\begin{array}{c}\text { Richardson } \\
\text { and Dodge }\end{array}$ & 2003 & Equine & $10 \mathrm{nM}-1 \mu \mathrm{M}$ & $24 \mathrm{~h}$ & $\begin{array}{c}\text { - collagen II, - MMP13, } \\
-\mathrm{MMP} 1,-\mathrm{MMP},+ \text { fibronectin }\end{array}$ \\
\hline
\end{tabular}

explant cultures. This may be due to a lower effective concentration in explants, as the drug must diffuse through the dense cartilage depending on treatment duration or a different homeostatic state of the cells in whole tissue versus cell monolayer. Chondrocytes in monolayer culture experience an entirely different set of external stimuli as compared to those suspended in a native $3 \mathrm{D}$ pericellular matrix, both through biological and mechanical signalling (Guilak et al., 2006). This could lead to a lack of external survival signals received by the monolayer chondrocytes after DEX exposure, rendering them unable to prevent apoptosis.

The relationship between DEX, autophagy and cell death is further complicated by a recent study on the effects of DEX on senescence in rat knee chondrocytes. Xue et al. (2016) found that a range of $0.25-128 \mu \mathrm{M}$ DEX activates autophagy and senescence in chondrocytes and that senescence increases after inhibiting autophagy with an mTOR inhibitor, potentially demonstrating that DEXinduced autophagy serves to protect chondrocytes from senescence. Senescence has been identified as a correlative factor for OA progression, so understanding the relationship between DEX dose and its activation of autophagy, apoptosis and senescence will be critical to understanding how to safely use it in patients.

\section{Non-arthritic chondrocyte cultures: effects on ECM gene expression}

Changes in the synthesis of ECM components at the cellular level alone do not seem to explain the effect of DEX on cartilage as a whole. Collagen II synthesis either decreases or does not significantly change after DEX treatment (Table 6) (James et al., 2007; Richardson and Dodge, 2003; Song et al., 2012). Song et al. (2012) found that DEX decreases the synthesis of aggrecan in healthy human chondrocytes. James et al. (2007) used an RNA microarray to assay the entire transcriptome of chondrocytes after DEX treatment and found that ECM genes as a whole are highly enriched in the DEX-treated group, although aggrecan and collagen II are not in the list of the most enriched ECM genes, which includes many of the other collagen family members, fibronectin, matrilin and laminin.

In healthy cartilage explant models, it is unclear whether DEX increases, decreases or does not affect cartilage GAG content, while the results from isolated cells suggest a complicated interplay in the regulation of ECM-remodelling factors by DEX. MMP-13, -1 and -3 are all significantly downregulated after DEX exposure (Richardson and Dodge, 2003) but the results of James et al. (2007) showed that several members of the ADAMTS family are among the most highly enriched ECM genes. Adding to the discussion of the dysregulation of matrix organisation by DEX, Hinek et al. (1984) reported that 100 nM DEX causes rabbit chondrocytes to deposit more elastic fibres in a more disorganised network. The relationship of the effects of DEX on aggrecan and metalloproteinase expression and the resulting effects on cartilage tissue structure as a whole have not yet been elucidated but is integral to understanding the results of studies such as the disperse collagen networks of Jaffré et al. (2003), as well as the safety of DEX for long-term joint treatment.

\section{Non-arthritic chondrocyte cultures: other affected pathways}

Several other pathways relevant to normal cartilage function are affected by DEX in isolated experiments. The results of the transcriptome screen done by James et al. (2007) identified the "metabolism" gene set as the most highly enriched in DEX-treated cells as compared to control, although no single metabolic pathway stood out as being upregulated as a whole. Glutathione S-transferases and aldehyde dehydrogenases, involved in several metabolic pathways, were some of the most notable individual genes. Studies using a non-arthritic embryonic mouse chondrocyte model found that SOX9, a transcription factor that activates chondrocyte differentiation, is upregulated after $100 \mathrm{nM}$ DEX treatment for $48 \mathrm{~h}$ (Jo et al., 2014; Sekiya et al., 2001). However, Song et al. (2012), using adult human chondrocytes, observed the opposite effect, which suggests that the effects of DEX could be dependent on the developmental state of the cells. Similarly, differences were noted by Bian et al. (2010) when using juvenile versus adult bovine tissue, different types of cartilage or samples from different species.

Fahey et al. (2009) reported an increase in CPPD crystal deposition in porcine chondrocytes caused by $96 \mathrm{~h}$ treatment with $10 \mathrm{nM}$ to $1 \mu \mathrm{MDEX}$ as a result of the upregulation of transglutaminase activity. CPPD crystals are suspected to contribute to joint damage in OA; thus, while DEX may help preserve PG and collagen structure of arthritic cartilage, it may also 
initiate other cell-mediated processes that become detrimental to joints (Fahey et al., 2009).

\section{Discussion}

The results of studies using DEX both in vivo and in vitro are highly dependent on model system, dosage and duration of DEX exposure. Understanding appropriate doses for glucocorticoids, in general, is vital for performing and comparing the results of clinical trials. For example, two separate trials studied the symptomatic benefits of TA on patients with knee OA (Kellgren-Lawrence grades 2 or 3): while Conaghan et al. (2018) found beneficial effects at 12 weeks using a single $32 \mathrm{mg}$ dose of i.a. extended-release TA, McAlindon et al. (2017) used $40 \mathrm{mg}$ i.a. injections of TA every 3 months for 2 years and reported a significant increase in cartilage volume loss. It is difficult to assess whether the differences in these outcomes are due to total dose, duration of treatment or both. Hence, a search into the literature was performed for clues from in vitro and animal studies. In this regard, the present review focuses on DEX alone, as studies have shown that different GCs with very different potencies can have different effects on cartilage cells and native tissues, as well as in various animal models (Dragoo et al., 2012; Mushtaq and Ahmed, 2002; Sadowski and Steinmeyer, 2001; Siengdee et al., 2009). Thus, it would be difficult to draw definite conclusions from such disparate studies about the safety or efficacy of the GC family as a whole.

Biological processes in cartilage that have been identified as being affected by DEX are highlighted in Fig. 1. While the results of studies on ECM synthesis in healthy isolated chondrocytes are inconsistent (James et al., 2007; Richardson and Dodge, 2003; Song et al., 2012), chronic administration of DEX at high doses was shown in some in vivo studies to have catabolic effects on initially healthy tissue (Annefeld and Erne, 1987; Glade et al., 1983; Podbielski et al., 1985). However, DEX may offer protection against the degenerative effects of arthritic diseases on ECM structure. At the tissue and cell level, DEX inhibits the production of matrix-degrading factors, rescuing matrix breakdown in arthritic contexts [Li et al., 2015; Lu et al., 2011; Wang et al. (2014) Dexamethasone treatment alters the response of human cartilage explants to inflammatory cytokines and mechanical injury as revealed by discovery proteomics. Osteoarthritis Cartilage 25: S381-S382]. While ECM content may be maintained, there may still be disruption of the matrix structure itself due to the dysregulation of cell-mediated remodelling factors, the effects of which on cartilage tissue in the long-term remain to be studied (Jaffré et al., 2003). One of the greatest challenges in comparing the results of various studies is the variety of model systems being used: isolated chondrocytes versus cartilage explant organ culture or co-culture of different joint tissues versus animal models and human clinical trials. While chondrocyte monoculture is useful for easier interrogation of molecular pathways, this approach cannot recapitulate the complex interactions of cells within their native 3D tissue matrix or between the different tissues of the joint. Even cultures incorporating chondrocytes suspended in a hydrogel to recapitulate the earliest stages of a 3D neo-tissue environment do not capture the same processes as it occurs in native tissues due to the differences in ECM composition, which complicates conclusions drawn about ECM synthesis and remodelling (Buschmann et al., 1995).

The overall effects of DEX on cell processes and viability remain unclear, as there are reports of both high and low doses of DEX either reducing or maintaining cell viability. DEX protects cartilage viability in an IL- $1 \alpha$ challenge of bovine cartilage explants (Li et al., 2015), but many studies using isolated chondrocytes have reported significant losses of cell viability after DEX exposure (Liu et al., 2014; Shen et al., 2015; Song et al., 2012; Zaman et al., 2014). One mechanism that may underlie loss of cell viability is the dysregulation of metabolism triggered by DEX, leading to upregulation of ROS within the chondrocytes. This process can trigger an autophagic response and, currently, conflicting reports exist in the literature on whether autophagy is the cause of chondrocyte apoptosis after DEX exposure or is protective against ROS-induced apoptosis and the answer likely depends on the dose of DEX used (Liu et al., 2014). ROS generation has been linked to catabolic effects in OA (Lepetsos and Papavassiliou, 2016), so the dose-dependent balance of ROS and autophagy in whole cartilage under arthritic conditions must be better understood. This, as well as the increase in CPPD crystal formation after DEX treatment reported by Fahey et al. (2009), could worsen the progression of the disease and more work must be done with human tissue to determine the extent of the risk. Autophagy is suppressed in arthritic contexts (Cheng et al., 2017), so the pro-autophagic response of DEX may serve to restore healthy homeostatic mechanisms and protect cartilage tissue, although this possibility has not yet been explored in the literature.

Studies with isolated cells seem to agree that DEX can reduce proliferation, which is also seen with higher DEX doses in cartilage tissue (Datuin et al., 2001). The anti-proliferative effect of DEX would be of great concern when treating young patients, as cartilage development could be disturbed upon DEX exposure (Datuin et al., 2001; Hainque et al., 1987; Maor and Silbermann, 1986; Miyazaki et al., 2000). Importantly, it is not known under what conditions and doses DEX drives cells towards quiescence, senescence or apoptosis. In vitro and in vivo, DEX exposure activates the p53/p21 pathway in tenocytes, a driving pathway towards senescence, although the effects of DEX on this pathway in cartilage are unknown (Poulsen et al., 2014). If DEX-induced reduction in proliferation as measured by ${ }^{3} \mathrm{H}$-thymidine incorporation is a result 
of a shift towards senescence, it could seriously affect the ability of cartilage tissue to respond to future challenges.

One aspect of DEX treatment that has not been wellexplored in the literature is the duration of specific cell and tissue responses after a given exposure to DEX. Some studies have been performed with other GCs, such as that of Behrens et al. (1976), using rabbits injected every week with $25 \mathrm{mg}$ hydrocortisone for 9 weeks. 26 weeks after hydrocortisone injections were stopped, metabolic rates increased towards normal along with an increase in cell proliferation, which was attributed to cells replicating to replace those killed by the multiple high-dose steroid injections, and the remaining cells restoring a more normal biosynthetic capacity. However, the extent to which the disrupted remodelling of the ECM can be rescued after such aggressive steroid treatment has not yet been explored, so it is unknown how the effects of the disruption of tissue remodelling factors may last and whether this could render the tissue more prone to disease in the future.

A question that must be discussed when studying any aspect of arthritis in vitro is whether the results would be different in a model of the entire joint, taking into account the cross-talk between cartilage, joint capsule synovium, bone and immune cells (Pelletier, 1999). The disease-modifying potential of DEX does not depend only on its effects on cartilage, but on the state of the joint as a whole. DEX was shown to reduce the transcription of some inflammatory cytokines in cartilage explants under arthritic stress, which would protect not only cartilage viability but potentially reduce inflammatory reactions of the surrounding joint tissues (Lu et al., 2011). As mentioned above, DEX reduces the production of MCP-1 in chondrocytes, reducing the potential for macrophage infiltration in RA, a possible mechanism of reducing RA disease progression (Koch et al., 1992). DEX also reduces cytokine expression by macrophages in an inflammatory environment, providing a potential protective mechanism against cytokine-induced damage in RA (Bartneck et al., 2014). The ROS-producing effect of DEX, while linked to apoptosis in chondrocytes, serves to increase the $\mathrm{T}$-cell suppressive capacity of anti-inflammatory macrophages, which has been linked to reducing the severity of RA in a mouse model (Gelderman et al., 2007; Kraaij et al., 2011). The synovium also secretes a large quantity of inflammatory cytokines immediately following a traumatic joint injury, a process which DEX suppresses in a rabbit model of post-traumatic OA, contributing to its apparent chondroprotective action (Huebner et al., 2014). In vitro, human cartilage-bone-synovium co-culture models of PTOA have also highlighted the potential of DEX in reducing cytokine release by synovium explants and thereby inhibiting proteolytic aggrecanGAG loss of cartilage [Dwivedi et al. (2019) Human cartilage-bone-synovium microphysiological system to study PTOA pathogenesis and treatment on Earth and in space. OAC 27: S167]. DEX also inhibits the production of COX-2 in the synovium in response to IL-1 $\beta$, a non-disease-modifying process that is used in several drugs on the market for treating OA and RA symptoms (Crofford et al., 1994; Laine et al., 2008; Sundy, 2001).

One of the most serious side effects of chronic GC treatment in humans is bone loss, which also occurs during arthritis progression (American College of Rheumatology Ad Hoc Committee on Glucocorticoid-Induced Osteoporosis, 2001; Hoes et al., 2015; Oelzner et al., 2010). After DEX treatment, healthy bone metabolism is affected, leading to changes in remodelling and eventual bone density loss and a reduction in load potential (Liu et al., 2015). It is unclear whether DEX worsens the progression of osteoporosis in arthritic animal models, but it is nonetheless worth exercising caution when considering the balance of side effects versus potential therapeutic gains (Islander et al., 2011; Oelzner et al., 2010; Quan et al., 2016). DEX also has been shown to stunt growth of developing bone and cartilage, explaining the effects of growth retardation and osteopenia seen in children treated with extended doses (Mushtaq and Ahmed, 2002; Tomaszewska et al., 2013). Side effects of DEX may also be ameliorated by combination treatments with other drugs such as antioxidants that combat its effects on metabolism, a combination that has already shown, in vivo, to improve the therapeutic capacity of DEX alone (Roy et al., 2013).

Finally, given the need for low dose treatment without use of multiple i.a. injections, improved drug delivery techniques are critically important for therapeutic treatment of OA/PTOA. Developing tools, such as nanocarriers or functionalised protein carriers, to aid in delivery of DEX specifically to the cartilage tissue will allow the drug to be given in single injection low-dose modalities, which may prevent its negative effects on cartilage tissue as well as systemic side effects (Bajpayee et al., 2016; Bajpayee and Grodzinsky, 2017; Geiger et al., 2018; Krishnan et al., 2018).

\section{Conclusions}

Considering the literature on DEX and the history of DEX use in OA and RA, treatment plans for clinical applications emphasise that beneficial effects of GCs are supported for i.a. administration at the lowest efficacious dose (Wernecke et al., 2015). Regarding $\mathrm{OA}$, it is important to distinguish between two different patient populations: those with wellestablished OA, mainly seeking pain relief, and those who have suffered a traumatic joint injury in a previously healthy joint. For the latter population, clinical and in vitro studies are looking toward the possibility that DEX (or other GCs) may ultimately 
prove to be disease-modifying if used immediately after injury and at low dose for a short enough duration (Grodzinsky et al., 2017; Lattermann et al., 2017). Thus, after a traumatic joint injury, which can progress to PTOA, treatment with DEX may prevent initial damage done by the release of inflammatory cytokines and maintain cartilage structure, lowering the chance of developing PTOA (Li et al., 2015). However, due to the potential for catabolic effects on cartilage and bone along with systemic side effects, chronic repeated high-dose administrations of DEX may do more harm than good to the joint and its use in the treatment of children is not advised due to its effects on growth and development. More work must be done in human models and clinical trials to discover what the long-term effects of DEXinduced dysregulation of cellular metabolism and ECM remodelling may be and whether DEX can aid in preventing PTOA after a traumatic joint injury. After decades of use in OA and RA patients, full understanding of the therapeutic potential of DEX, along with other GC family members, may only now be coming to light, although much more careful and consistent study and optimisation of treatment remain to be done.

\section{Acknowledgements}

The authors declare no conflicts of interest and would like to thank Dr Brianne Connizzo for academic discussion during the development of the present review. The work was supported by the NIH/NCATS Grant UG3/UH3 TR00218.

\section{References}

American College of Rheumatology Ad Hoc Committee on Glucocorticoid-Induced Osteoporosis (2001) Recommendations for the prevention and treatment of glucocorticoid-induced osteoporosis: 2001 update. Arthritis Rheum 44: 1496-1503.

Annefeld M, Erne B (1987) The mode of action of a glycosaminoglycan-peptide-complex (Rumalon) on articular cartilage of the rat in vivo. Clin Rheumatol 6: 340-349.

Arroll B, Goodyear-Smith F (2004) Corticosteroid injections for osteoarthritis of the knee: meta-analysis. BMJ 328: 869. DOI: 10.1136/bmj.38039.573970.7C.

Ashraf S, Mapp PI, Walsh DA (2011) Contributions of angiogenesis to inflammation, joint damage, and pain in a rat model of osteoarthritis. Arthritis Rheum 63: 2700-2710.

Bajpayee AG, Grodzinsky AJ (2017) Cartilagetargeted drug delivery: can electrostatic interactions help? Nat Rev Rheumatol 13: 183-193.

Bajpayee AG, Quadir MA, Hammond PT, Grodzinsky AJ (2016) Charge based intra-cartilage delivery of single dose dexamethasone using avidin nano-carriers suppresses cytokine-induced catabolism long term. Osteoarthritis Cartilage 24: 71-81.

Bajpayee AG, Scheu M, Grodzinsky AJ, Porter RM (2015) A rabbit model demonstrates the influence of cartilage thickness on intra-articular drug delivery and retention within cartilage. J Orthop Res 33: 660667.

Bajpayee AG, Scheu M, Grodzinsky AJ, Porter RM (2014) Electrostatic interactions enable rapid penetration, enhanced uptake and retention of intraarticular injected avidin in rat knee joints. J Orthop Res 32: 1044-1051.

Bartneck M, Peters FM, Warzecha KT, Bienert $\mathrm{M}$, van Bloois $\mathrm{L}$, Trautwein $\mathrm{C}$, Lammers T, Tacke $\mathrm{F}$ (2014) Liposomal encapsulation of dexamethasone modulates cytotoxicity, inflammatory cytokine response, and migratory properties of primary human macrophages. Nanomedicine 10: 1209-1220.

Behrens F, Shepard N, Mitchell N (1976) Metabolic recovery of articular cartilage after intra articular injections of glucocorticoid. J Bone Joint Surg Am 58: 1157-1160.

Benedek TG (2011) History of the development of corticosteroid therapy. Clin Exp Rheumatol 29: S5-S12.

Bian L, Stoker AM, Marberry KM, Ateshian GA, Cook JL, Hung CT (2010) Effects of dexamethasone on the functional properties of cartilage explants during long-term culture. Am J Sports Med 38: 78-85.

Bordag N, Klie S, Jürchott K, Vierheller J, Schiewe H, Albrecht V, Tonn JC, Schwartz C, Schichor C, Selbig J (2015) Glucocorticoid (dexamethasone)induced metabolome changes in healthy males suggest prediction of response and side effects. Sci Rep 5:15954. DOI: 10.1038/srep15954.

Buschmann MD, Gluzband YA, Grodzinsky AJ, Hunziker EB (1995) Mechanical compression modulates matrix biosynthesis in chondrocyte/ agarose culture. J Cell Sci 108: 1497-1508.

Busschers E, Holt JP, Richardson DW (2010) Effects of glucocorticoids and interleukin-1 $\beta$ on expression and activity of aggrecanases in equine chondrocytes. Am J Vet Res 71: 176-185.

Chan MM, Moore AR (2010) Resolution of inflammation in murine autoimmune arthritis is disrupted by cyclooxygenase- 2 inhibition and restored by prostaglandin E2-mediated lipoxin A4 production. J Immunol 184: 6418-6426.

Cheng NT, Meng H, Ma LF, Zhang L, Yu HM, Wang ZZ, Guo A (2017) Role of autophagy in the progression of osteoarthritis: the autophagy inhibitor, 3-methyladenine, aggravates the severity of experimental osteoarthritis. Int J Mol Med 39: 1224-1232.

Conaghan PG, Hunter DJ, Cohen SB, Kraus VB, Berenbaum F, Lieberman JR, Jones DG, Spitzer AI, Jevsevar DS, Katz NP, Burgess DJ, Lufkin J, Johnson R, Bodick N (2018) Effects of a single intraarticular injection of a microsphere formulation of triamcinolone acetonide on knee osteoarthritis pain. J Bone Joint Surg Am 100: 666-677. 
Connizzo BK, Grodzinsky AJ (2019) Low-dose administration of dexamethasone is beneficial in preventing secondary tendon damage in a stressdeprived joint injury explant model. J Orthop Res. DOI: 10.1002/jor.24451 [Epub ahead of print].

Creamer P (1999) Intra-articular corticosteroid treatment in osteoarthritis. Curr Opin Rheumatol 11: 417-421.

Crofford LJ, Wilder RL, Ristimaki AP, Sano H, Remmers EF, Epps HR, Hla T (1994) Cyclooxygenase-1 and -2 expression in rheumatoid synovial tissues. Effects of interleukin-1 $\beta$, phorbol ester, and corticosteroids. J Clin Invest 93: 1095-1101.

D'Lima DD, Hashimoto S, Chen PC, Lotz MK, Colwell CW Jr (2001) Prevention of chondrocyte apoptosis. J Bone Joint Surg Am 83-A Suppl 2: 25-26.

Datuin JP, Ng KP, Hayes TB, Bern HA (2001) Effects of glucocorticoids on cartilage growth and response to IGF-I in the tilapia (Oreochromis mossambicus). Gen Comp Endocrinol 121: 289-294.

Dearden LC, Mosier HD, Brundage M, Thai C, Jansons R (1986) The effects of different steroids on costal and epiphyseal cartilage of fetal and adult rats. Cell Tissue Res 246: 401-412.

Dragoo JL, Danial CM, Braun HJ, Pouliot MA, Kim HJ (2012) The chondrotoxicity of single-dose corticosteroids. Knee Surg Sports Traumatol Arthrosc 20: 1809-1814.

Fahey M, Mitton E, Muth E, Rosenthal AK (2009) Dexamethasone promotes calcium pyrophosphate dihydrate crystal formation by articular chondrocytes. J Rheumatol 36: 163-169.

Garvican ER, Vaughan-Thomas A, Redmond C, Gabriel N, Clegg PD (2010) MMP-mediated collagen breakdown induced by activated protein $\mathrm{C}$ in equine cartilage is reduced by corticosteroids. J Orthop Res 28: 370-378.

Geiger BC, Wang S, Padera PF, Grodzinsky AJ, Hammond PT (2018) Cartilage penetrating nanoparticles improve delivery and efficacy of growth factor in treatment of osteoarthritis. Sci Transl Med 10. DOI: $10.1126 /$ scitranslmed.aat 8800 .

Gelderman KA, Hultqvist M, Pizzolla A, Zhao M, Nandakumar KS, Mattsson R, Holmdahl R (2007) Macrophages suppress $T$ cell responses and arthritis development in mice by producing reactive oxygen species. J Clin Invest 117: 3020-3028.

Geng Y, Blanco FJ, Cornelisson M, Lotz M (1995) Regulation of cyclooxygenase-2 expression in normal human articular chondrocytes. J Immunol 155: 796801.

Gibson T, Burry HC, Poswillo D, Glass J (1977) Effect of intra-articular corticosteroid injections on primate cartilage. Ann Rheum Dis 36: 74-79.

Glade MJ, Krook L, Schryver HF, Hintz HF (1983) Morphologic and biochemical changes in cartilage of foals treated with dexamethasone. Cornell Vet 73: 170-192.

Grodzinsky AJ, Wang Y, Kakar S, Vrahas MS, Evans CH (2017) Intra-articular dexamethasone to inhibit the development of post-traumatic osteoarthritis. J Orthop Res 35: 406-411.

Guilak F, Alexopoulos LG, Upton ML, Youn I, Choi JB, Cao L, Setton LA, Haider MA (2006) The pericellular matrix as a transducer of biomechanical and biochemical signals in articular cartilage. Ann N Y Acad Sci 1068: 498-512.

Hainque B, Dominice J, Jaffray P, Ronot X, Adolphe M (1987) Effects of dexamethasone on the growth of cultured rabbit articular chondrocytes: relation with the nuclear glucocorticoid-receptor complex. Ann Rheum Dis 46: 146-152.

Heard BJ, Barton KI, Chung M, Achari Y, Shrive NG, Frank CB, Hart DA (2015) Single intra-articular dexamethasone injection immediately post-surgery in a rabbit model mitigates early inflammatory responses and post-traumatic osteoarthritis-like alterations. J Orthop Res 33: 1826-1834.

Hepper CT, Halvorson JJ, Duncan ST, Gregory AJ, Dunn WR, Spindler KP (2009) The efficacy and duration of intra-articular corticosteroid injection for knee osteoarthritis: a systematic review of level I studies. J Am Acad Orthop Surg 17: 638-646.

Hinek A, Kawiak J, Czarnowska E, Barcew B (1984) The effect of agarose and dexamethasone on the nature and production of extracellular matrix components by elastic cartilage chondrocytes. Acta Biol Hung 35: 245-258.

Hoes JN, Bultink IE, Lems WF (2015) Management of osteoporosis in rheumatoid arthritis patients. Expert Opin Pharmacother 16: 559-571.

Hollander JL, Brown EM, Jessar RA, Brown CY (1951) Hydrocortisone and cortisone injected into arthritic joints: comparative effects of and use of hydrocortisone as a local antiarthritic agent. JAMA 147: 1629-1635.

Hollander JL (1960) Clinical use of dexamethasone: role in treatment of patients with arthritis. JAMA 172: 306-310.

Huebner KD, Shrive NG, Frank CB (2014) Dexamethasone inhibits inflammation and cartilage damage in a new model of post-traumatic osteoarthritis. J Orthop Res 32: 566-572.

Islander U, Jochems C, Stubelius A, Andersson A, Lagerquist MK, Ohlsson C, Carlsten H (2011) Combined treatment with dexamethasone and raloxifene totally abrogates osteoporosis and joint destruction in experimental postmenopausal arthritis. Arthritis Res Ther 13: R96. DOI:10.1186/ar3371.

Jaffré B, Watrin A, Loeuille D, Gillet P, Netter P, Laugier P, Saïed A (2003) Effects of antiinflammatory drugs on arthritic cartilage: a high-frequency quantitative ultrasound study in rats. Arthritis Rheum 48: 1594-1601.

James CG, Ulici V, Tuckermann J, Michael TM, Beier $\mathrm{F}$ (2007) Expression profiling of dexamethasonetreated primary chondrocytes identifies targets of glucocorticoid signalling in endochondral bone development. BMC Genomics 8: 205. DOI: 10.1186/1471-2164-8-205. 
Jo A, Denduluri S, Zhang B, Wang Z, Yin L, Yan Z, Kang R, Shi LL, Mok J, Lee MJ, Haydon RC (2014) The versatile functions of Sox 9 in development, stem cells, and human diseases. Genes Dis 1: 149-161.

Jüni P, Hari R, Rutjes AW, Fischer R, Silletta MG, Reichenbach S, da Costa BR (2015) Intraarticular corticosteroid for knee osteoarthritis. Cochrane Database Syst Rev 10: CD005328. DOI: 10.1002/14651858.CD005328.pub3.

Koch AE, Kunkel SL, Harlow LA, Johnson B, Evanoff HL, Haines GK, Burdick GK, Pope RM, Strieter RM (1992) Enhanced production of monocyte chemoattractant protein-1 in rheumatoid arthritis. The J Clin Invest 90: 772-779.

Kraaij MD, van der Kooij SW, Reinders ME, Koekkoek K, Rabelink TJ, van Kooten C, Gelderman KA (2011) Dexamethasone increases ROS production and $T$ cell suppressive capacity by anti-inflammatory macrophages. Mol Immunol 49: 549-557.

Krishnan Y, Rees HA, Rossitto CP, Kim SE, Hung HK, Frank EH, Olsen BD, Liu DR, Hammond PT, Grodzinsky AJ (2018) Green fluorescent proteins engineered for cartilage-targeted drug delivery: insights for transport into highly charged avascular tissues. Biomaterials 183: 218-233.

Laine L, White WB, Rostom A, Hochberg M (2008) COX-2 selective inhibitors in the treatment of osteoarthritis. Semin Arthritis Rheum 38: 165-187.

Lattermann C, Jacobs CA, Proffitt Bunnell M, Huston LJ, Gammon LG, Johnson DL, Reinke EK, Huebner JL, Kraus VB, Spindler KP (2017) A multicenter study of early anti-inflammatory treatment in patients with acute anterior cruciate ligament tear. Am J Sports Med 45: 325-333.

Lepetsos P, Papavassiliou AG (2016) ROS/ oxidative stress signaling in osteoarthritis. Biochim Biophys Acta 1862: 576-591.

Li Y, Wang Y, Chubinskaya S, Schoeberl B, Florine E, Kopesky P, Grodzinsky AJ (2015) Effects of insulinlike growth factor- 1 and dexamethasone on cytokinechallenged cartilage: relevance to post-traumatic osteoarthritis. Osteoarthritis Cartilage 23: 266-274.

Liu N, Wang W, Zhao Z, Zhang T, Song Y (2014) Autophagy in human articular chondrocytes is cytoprotective following glucocorticoid stimulation. Mol Med Rep 9: 2166-2172.

Liu Y, Cui Y, Chen Y, Gao X, Su Y, Cui L (2015) Effects of dexamethasone, celecoxib, and methotrexate on the histology and metabolism of bone tissue in healthy Sprague Dawley rats. Clin Interv Aging 10: 1245-1253.

Lu Y, Evans CH, Grodzinsky AJ (2011) Effects of short-term glucocorticoid treatment on changes in cartilage matrix degradation and chondrocyte gene expression induced by mechanical injury and inflammatory cytokines. Arthritis Res Ther 13: R142. DOI: 10.1186/ar3456.

Malfait AM, Tortorella M, Thompson J, Hills R, Meyer DM, Jaffee BD, Chinn K, Ghoreishi-Haack N, Markosyan S, Arner EC (2009) Intra-articular injection of tumor necrosis factor- $\alpha$ in the rat: an acute and reversible in vivo model of cartilage proteoglycan degradation. Osteoarthritis Cartilage 17: 627-635.

Mankin HJ, Zarins A, Jaffe WL (1972) The effect of systemic corticosteroids on rabbit articular cartilage. Arthritis Rheum 15: 593-599.

Manson SC, Brown RE, Cerulli A, Vidaurre CF (2009) The cumulative burden of oral corticosteroid side effects and the economic implications of steroid use. Respir Med 103: 975-994.

Maor G, Silbermann M (1986) Supraphysiological concentrations of dexamethasone induce elevation of calcium uptake and depression of $[3 \mathrm{H}]$-thymidine incorporation into DNA in cartilage in vitro. Calcif Tissue Int 39: 284-290.

McAlindon TE, LaValley MP, Harvey WF, Price LL, Driban JB, Zhang M, Ward RJ (2017) Effect of intra-articular triamcinolone vs saline on knee cartilage volume and pain in patients with knee osteoarthritis. JAMA 317: 1967-1795.

McCoy JM, Wicks JR, Audoly LP (2002) The role of prostaglandin E2 receptors in the pathogenesis of rheumatoid arthritis. J Clin Invest 110: 651-658.

Miyazaki Y, Tsukazaki T, Hirota Y, Yonekura A, Osaki M, Shindo H, Yamashita S (2000) Dexamethasone inhibition of TGF beta-induced cell growth and type II collagen mRNA expression through ERK-integrated AP-1 activity in cultured rat articular chondrocytes. Osteoarthritis Cartilage 8: 378-385.

Mushtaq T, Ahmed SF (2002) The impact of corticosteroids on growth and bone health. Arch Dis Child 87: 93-96.

Mushtaq T, Farquharson C, Seawright E, Ahmed SF (2002) Glucocorticoid effects on chondrogenesis, differentiation and apoptosis in the murine ATDC5 chondrocyte cell line. J Endocrinol 175: 705-713.

Oelzner P, Fleissner-Richter S, Bräuer R, Hein G, Wolf G, Neumann T (2010) Combination therapy with dexamethasone and osteoprotegerin protects against arthritis-induced bone alterations in antigen-induced arthritis of the rat. Inflamm Res 59: 731-741.

Palmer G, Guerne PA, Mezin F, Maret M, Guicheux J, Goldring MB, Gabay C (2002) Production of interleukin-1 receptor antagonist by human articular chondrocytes. Arthritis Res 4: 226-231.

Pelletier JP (1999) The influence of tissue crosstalking on OA progression: role of nonsteroidal antiinflammatory drugs. Osteoarthritis Cartilage 7: 374-376.

Podbielski A, Raiss R (1985) Dose related effects of dexamethasone treatment on the ultrastructure of articular cartilage in rats. Agents Actions 17: 322-324.

Poulsen RC, Watts AC, Murphy RJ, Snelling SS, Carr AJ, Hulley PA (2014) Glucocorticoids induce senescence in primary human tenocytes by inhibition of sirtuin 1 and activation of the p53/p21 pathway: in vivo and in vitro evidence. Ann Rheum Dis 73: 14051413.

Quan L, Zhang Y, Dusad A, Ren K, Purdue PE, Goldring SR, Wang D (2016) The evaluation of the therapeutic efficacy and side effects of a 
macromolecular dexamethasone prodrug in the collagen-induced arthritis mouse model. Pharm Res 33: 186-193.

Rauchhaus U, Schwaiger FW, Panzner S (2009) Separating therapeutic efficacy from glucocorticoid side-effects in rodent arthritis using novel, liposomal delivery of dexamethasone phosphate: long-term suppression of arthritis facilitates interval treatment. Arthritis Res Ther 11: R190. DOI: 10.1186/ar2889.

Richardson DW, Dodge GR(2003) Dose-dependent effects of corticosteroids on the expression of matrixrelated genes in normal and cytokine-treated articular chondrocytes. Inflamm Res 52: 39-49.

Roach BL, Kelmendi-Doko A, Balutis EC, Marra KG, Ateshian GA, Hung CT (2016) Dexamethasone release from within engineered cartilage as a chondroprotective strategy against interleukin-1 $\alpha$. Tissue Eng Part A 22: 621-632.

Roy S, Sannigrahi S, Ghosh B, Pusp P, Roy T (2013) Combination therapy of dexamethasone with epigallocatechin enhances tibiotarsal bone articulation and modulates oxidative status correlates with cartilage cytokines expression in the early phase of experimental arthritis. Eur J Pharmacol 698: 444454.

Sadowski T, Steinmeyer J (2001) Effects of nonsteroidal antiinflammatory drugs and dexamethasone on the activity and expression of matrix metalloproteinase-1, matrix metalloproteinase-3 and tissue inhibitor of metalloproteinases- 1 by bovine articular chondrocytes. Osteoarthritis Cartilage 9: 407-415.

Saito S, Katoh M, Masumoto M, Matsumoto S, Masuho Y (1999) Dexamethasone inhibits collagen degradation induced by the combination of interleukin-1 and plasminogen in cartilage explant culture. Biol Pharm Bull 22: 727-730.

Saklatvala J (2002) Glucocorticoids: do we know how they work? Arthritis Res 4: 146-150.

Sekiya I, Koopman P, Tsuji K, Mertin S, Harley V, Yamada Y, Shinomiya K, Nifuji A, Noda M (2001) Dexamethasone enhances SOX9 expression in chondrocytes. J Endocrinol 169: 573-579.

Shalom-Barak T, Quach J, Lotz M (1998) Interleukin17-induced gene expression in articular chondrocytes is associated with activation of mitogen-activated protein kinases and NF-kappaB. J Biol Chem 273: 27467-27473.

Sheibanie AF, Khayrullina T, Safadi FF, Ganea D (2007): Prostaglandin E2 exacerbates collageninduced arthritis in mice through the inflammatory interleukin-23/interleukin-17 axis. Arthritis Rheum 56: 2608-2619.

Shen C, Cai GQ, Peng JP, Chen XD (2015) Autophagy protects chondrocytes from glucocorticoidsinduced apoptosis via ROS/Akt/FOXO3 signaling. Osteoarthritis Cartilage 23: 2279-2287.

Siengdee P, Radeerom T, Kuanoon S, Euppayo T, Pradit W, Chomdej S, Ongchai S, Nganvongpanit K (2015) Effects of corticosteroids and their combinations with hyaluronanon on the biochemical properties of porcine cartilage explants. BMC Vet Res 11: 298. DOI: 10.1186/s12917-015-0611-6.

Song YW, Zhang T, Wang WB (2012) Gluococorticoid could influence extracellular matrix synthesis through Sox9 via p38 MAPK pathway. Rheumatol Int 32: 3669-3673.

Stöve J, Schoniger R, Huch K, Brenner R, Gunther KP, Puhl W, Scharf HP (2002) Effects of dexamethasone on proteoglycan content and gene expression of IL-1beta-stimulated osteoarthrotic chondrocytes in vitro. Acta Orthop Scand 73: 562-567.

Stueber T, Karsten J, Stoetzer C, Leffler A (2014) Differential cytotoxic properties of drugs used for intra-articular injection on human chondrocytes: an experimental in-vitro study. Eur J Anaesthesiol 31: 640-645.

Subramanian A, Tamayo P, Mootha VK, Mukherjee S, Ebert BL, Gillette MA, Paulovich A, Pomeroy SL, Golub TR, Lander ES, Mesirov JP (2005) Gene set enrichment analysis: a knowledge-based approach for interpreting genome-wide expression profiles. Proc Natl Acad Sci U S A 102: 15545-15550.

Sundy JS (2001) COX-2 inhibitors in rheumatoid arthritis. Curr Rheumatol Rep 3: 86-91.

Tomaszewska E, Dobrowolski P, Puzio I (2013) Morphological changes of the cartilage and bone in newborn piglets evoked by experimentally induced glucocorticoid excess during pregnancy. J Anim Physiol Anim Nutr (Berl) 97: 785-796.

Tu Y, Xue H, Francis W, Davies AP, Pallister I, Kanamarlapudi V, Xia Z (2013) Lactoferrin inhibits dexamethasone-induced chondrocyte impairment from osteoarthritic cartilage through up-regulation of extracellular signal-regulated kinase $1 / 2$ and suppression of FASL, FAS, and caspase 3. Biochem Biophys Res Commun 441: 249-255.

Villiger PM, Terkeltaub R, Lotz M (1992) Monocyte chemoattractant protein-1 (MCP-1) expression in human articular cartilage. Induction by peptide regulatory factors and differential effects of dexamethasone and retinoic acid. J Clin Invest 90: 488-496.

Wang T, Yang J, Che X, Zhao K, Wang J, Zhang Y, Zhao J, Ga Y (2017a) Systems study on the antirheumatic mechanism of Tibetan medicated-bath therapy using Wuwei-Ganlu-Yaoyu-Keli. BioMed Res Int 2017: 1-10.

Wernecke C, Braun HJ, Dragoo JL (2015) The effect of intra-articular corticosteroids on articular cartilage: a systematic review. Orthop J Sports Med 3: 2325967115581163 . DOI: 10.1177/2325967115581163.

Wieland HA, Michaelis M, Kirschbaum BJ, Rudolphi KA (2005) Osteoarthritis - an untreatable disease? Nat Rev Drug Discov 4: 331-344.

Xue E, Zhang Y, Song B, Xiao J, Shi Z (2016) Effect of autophagy induced by dexamethasone on senescence in chondrocytes. Mol Med Rep 14: 30373044.

Zaman F, Chrysis D, Huntjens K, Chagin A, Takigawa M, Fadeel B, Sävendahl L (2014) Dexamethasone differentially regulates Bcl-2 family 
proteins in human proliferative chondrocytes: role of pro-apoptotic Bid. Toxicol Lett 224: 196-200.

Zeng C, Lane NE, Hunter DJ, Wei J, Choi HK, McAlindon TE, Li H, Lu N, Lei G, Zhang Y (2019) Intra-articular corticosteroids and the risk of knee osteoarthritis progression: results from the Osteoarthritis Initiative. Osteoarthritis Cartilage 27: 855-862.

\section{Web References}

1. https://clinicaltrials.gov/ct2/show/study/ NCT02271698 [10-09-2018]

2. https://clinicaltrials.gov/ct2/show/NCT01612702 [10-09-2018]

\section{Discussion with Reviewers}

Chris Evans: If you had symptomatic knee OA, would you agree to receive i.a. DEX? If so, at what dose and frequency?

Authors: This question highlights the crucially different needs of patients who have well-developed OA (and, thus, need pain relief) versus those who have just sustained a traumatic knee injury to a previously healthy knee. Associated with this dichotomy is the use of a GC such as DEX for pain relief versus the potential use of a GC for OA disease modification at the earliest stage post-injury. For symptomatic knee OA (after discussion with a physician), we would first request a non-steroidal painkiller before moving on to DEX (to avoid any potential side effects, given the typically high doses used in i.a. injections). If knee OA had progressed to the point of being symptomatic, the potential disease-modifying effects of DEX may be too little too late to have a significant protective effect on cartilage, as once cartilage has degraded, DEX would not bring it back. Nevertheless, pain mediation by DEX acting on tissues/sites other than cartilage may be effective. In contrast, after sustaining a traumatic joint injury where early intervention could prevent the long-term progression to post-traumatic OA, we would seriously consider a single low dose of DEX to protect cartilage from the early inflammatory and catabolic responses to the injury, consistent with the methods of the ongoing clinical trial at the Mayo Clinic (NCT02318433). Finally, regarding dose, we recognise that the typical concentration of DEX used clinically for i.a. injections is almost six orders of magnitude higher than that reported to achieve cartilage protection in several arthritic explant models described above. Progress in targeted drug delivery to cartilage (and other joint tissues) could substantially reduce the effective dose of i.a. DEX needed and, thereby, minimise off-target side effects.

Ryan Porter: Many of the drug carriers tested for sustained GC release within the joint are designed for delivery to the synovial cavity, from where they can target multiple joint tissues. This includes the microsphere-based formulation referred to in the literature as FX006 (Conaghan et al., 2018), which is currently under clinical evaluation. However, a very recent paper from Rudnik-Jansen et al. (2019, additional reference) reported that an alternative microparticle-based delivery approach leads to enhanced joint instability in rats subjected to combined ACL transection and partial medial meniscectomy, when compared to single bolus delivery at the same GC dose. This report suggests that, for drugs formulations involving release from the synovial cavity, the GC-dose response must be considered for all joint tissues that impact joint stability, not just cartilage. Based on these results, what place do continued cartilage-specific models have in the future evaluation of GCs as diseasemodifying drugs for PTOA?

Authors: The reviewer has raised several very important issues including (1) the need for multitissue models of OA/PTOA, (2) the differing aims of sustained delivery [as documented in the rat model used by Rudnik-Jansen et al. (2019, additional reference)] versus tissue-targeted drug delivery, both through the synovial cavity, and, more generally, (3) what we can learn from in vitro versus animal models of disease. OA and PTOA are now long acknowledged to be diseases of the entire joint, not just cartilage alone. One of the main concerns about GC treatment has been the potential for degeneration of cartilage; hence, the authors' focus has been to review the disparate reports available in the literature about DEX treatment of cartilage and chondrocytes. The study of cartilage alone is relevant to the understanding of how chondrocytes behave in the context of isolated cells versus intact tissue explants and in vivo systems, to allow a better understanding of cellular mechanisms. However, for relevance to i.a. treating of humans, it is imperative to have additional in vitro models that reflect the multi-tissue response to GCs (or other drugs). Recent examples include the effects of DEX on mechanically injured human osteochondral plugs co-cultured with explants of inflamed joint capsule synovium harvested from the same human knees [Dwivedi et al. (2019) Human cartilage-bone-synovium microphysiological system to study PTOA pathogenesis and treatment on Earth and in space. OAC 27: S167], as well as effects of DEX on tendon viability in murine bone-tendon-muscle explant cultures in which inflammatory cytokines are released by muscle and/or bone (Connizzo and Grodzinsky, 2019). Such co-culture systems can further highlight the positive or negative effects of GCs associated with the interactions between multiple tissues.

The issue of sustained release versus tissuetargeted treatment reflects the differing needs of longer-term pain management in human OA versus early treatment post-injury to prevent PTOA. Since cartilage has no nerve supply, it is clearly not the target for pain relief; other sites including 
the synovium present more appropriate targets. However, cartilage and/or other joint tissues may be targeted early after injury to mitigate against initial inflammatory and mechanical insults post-injury. In this regard, the choice of model system (e.g. in vitro culture versus animal) is quite important. While rodent (e.g. mouse and rat) models are extremely useful in pre-clinical studies to unravel the biology of the response to drug treatment, these models alone cannot confirm translation to humans in terms of delivery to target cells inside joint tissues. Targeting cells deep within the full thickness of a given tissue such as cartilage requires consideration of diffusive transport of drugs into tissues. Mouse knee cartilage is only about $50 \mu \mathrm{m}$ thick, rat knee cartilage is about $100 \mu \mathrm{m}$ thick, while human cartilage (1-2.5 mm thick) is $~ 20-50$ times thicker. The characteristic diffusion time of a molecule from synovial fluid into the full depth of cartilage is proportional to the square of the tissue thickness (Bajpayee and Grodzinsky, 2017), thus 100-400 times longer for full thickness human cartilage as compared to rat cartilage and 400-2,500 times longer diffusive penetration time in human than mouse cartilage. Thus, sustained release can represent a trade-off between the need to extend residence time in the synovial fluid long enough for penetration into the tissue (e.g. cartilage) and the potential problem of sustained presence of a drug as suggested by Rudnik-Jansen et al. (2019, additional reference). In contrast, intra-cartilage targeting can enable a single very low-dose bolus of a GC into full thickness cartilage; for example, when mmthick cartilage explants are subjected to a significant inflammatory challenge in vitro, a single low-dose bolus of DEX is cartilage-protective when the DEX is functionalised to a cartilage-targeting nanoparticle that can penetrate into the full depth of the explant within $24 \mathrm{~h}$ (Bajpayee et al., 2016). Such (cationic) nanoparticles rapidly penetrate into cartilage, tendon, ligaments, meniscus and fat pad when injected intraarticularly into rabbit and rat knees in vivo (Bajpayee et al., 2014, 2015).

Ryan Porter: A central limitation to GC use is that they alter multiple signalling pathways within the same target cell, such as in chondrocytes. Given the complexity of GC action, might it be better to use a combination of drugs that more specifically target known pathways involved in OA pathogenesis, such as NF- $\kappa \mathrm{B}$-mediated catabolic gene expression and chondrocyte autophagy? Does the continued pursuit of GCs reflect a limitation to the current paradigm of single-drug therapeutics?
Authors: We completely agree with the reviewer that a combination drugs will ultimately be needed. We and others (Wieland et al., 2005) believe that a single "magic bullet" drug that not only reduces degenerative processes and pain, but regenerates damaged cartilage, will never exist because of the multiple diverse risk factors for initiation and progression of OA/PTOA. A variety of drugs, perhaps in combination with an anti-inflammatory GC may be needed. Similar to GCs, drugs targeting major regulators such as $\mathrm{NF}-\kappa \mathrm{B}$ or the mTOR pathway that regulates autophagy can affect many cellular processes, not just limited to those that directly relate to OA progression. More research is necessary to characterise whether a broad-spectrum antiinflammatory GC such DEX or a drug more targeted to a single pathway (along or in combination) may be a safer option on a case-by-case basis and whether combinations of single-target drugs might be desirable. Research involving a GC such as DEX can also help to discover additional relevant pathways, such as the potential regulatory role of JNK $1 / 2$ in the progression of cartilage degradation by observing the phosphorylation pathways affected by DEX in an IL-1 $\alpha$ challenged explant culture system, which suggests the role of a JNK inhibitor as a potential drug candidate [Ismail et al., 2016, additional reference; Wang et al. (2017b) Phosphoproteomics analysis of signaling changes in human chondrocytes following treatment with Il-1, IGF-1 and dexamethasone. Osteoarthritis Cartilage 25: S165-S166].

\section{Additional Reference}

Ismail HM, Miotla-Zarebska J, Troeberg L, Tang X, Stott B, Yamamoto K, Nagase H, Fosang AJ, Vincent TL, Saklatvala J (2016) JNK-2 controls aggrecan degradation in murine articular cartilage and the development of experimental osteoarthritis. Arthritis Rheum 68: 1165-1171.

Rudnik-Jansen I, Tellegen AR, Pouran B, Schrijver K, Meij BP, Emans PJ, de Gendt E, Thomas RE, Kik MJL, de Visser HM, Weinans H, Egas A, van Maarseveen E, Woike N, Mihov G, Thies J, Tryfonidou MA, Creemers LB (2019) Local controlled release of corticosteroids extends surgically induced joint instability by inhibiting tissue healing. Br J Pharmacol 176: 4050-4064.

Editor's note: The Scientific Editor responsible for this paper was Martin Stoddart. 